\section{Visualizing and Understanding the Science of Climate Change}

Barraged by contradictory messages from media, many don't have the right tools to know what to think about the connection between human activity and our changing climate. This project brings together chemists and educators from the IUPAC Committee on Chemistry Education, The King's Centre for Visualization in Science (Canada), The Royal Society of Chemistry (UK), American Chemical Society (USA), UNESCO, and the Federation of African Societies of Chemistry to develop a set of critically reviewed, interactive, web-based materials for global dissemination to help students visualize and understand the underlying science of climate change. Target audiences are (a) teachers at the secondary and first-year tertiary levels, (b) students at those same levels, and (c) chemistry professionals. Visualizations will emphasize the fundamental chemistry of climate processes, but will also present research climate models, and place anthropogenic inputs to our atmosphere in a geo-political context.

The outcomes will contribute to the International Year of Chemistry's goal of promoting the critical role of "education in and about chemistry" in "addressing challenges such as global climate change, in providing sustainable sources of clean water, food and energy, and in maintaining a wholesome environment for the well being of all people...."

For more information and comments, contact Task Group Chair Peter Mahaffy <peter.mahaffy@kingsu.ca〉.

\section{Sinitisw. ww.iupac.org/web/ins/2008-043-1-050}

\section{A Critical Evaluation of the Viscosity and Density of Molten Copper and} Tin

There is an increasing use of mathematical models to simulate a variety of processes involving liquid metals such as "cast to shape," primary and secondary metal production, powder production by spray forming, and welding. Depending on what aspect of the process is modeled, there is a need for viscosity data for the relevant metals or their alloys.

Historically, there are wide discrepancies in the viscosity data reported for the metallic elements and for alloys (1) and in general reported values for viscosity can be up to an order of magnitude apart. Hence, only an internationally accepted committee can collect and critically evaluate such data.

In a previous IUPAC project standard reference correlations for the viscosity and density of aluminium and iron were proposed (2). The proposed standard reference correlations for the density of aluminium and iron are characterized by $0.65 \%$ and $0.77 \%$ percentage standard deviation, while the standard reference correlations for the viscosity are characterized by $13.7 \%$ and $5.7 \%$ percentage standard deviation, at the $95 \%$ confidence level, respectively.

The viscosity and density of aluminium covered a temperature range 930-1270 $\mathrm{K}$ and iron 1800-2100 $\mathrm{K}$. The proposed study of copper and tin will cover the temperature ranges $1350-1700 \mathrm{~K}$ and $500-1050$ $\mathrm{K}$, respectively, and thus will provide a complete temperature range for the viscosity and density from 500-2100 K for industrial application.

\section{References}

1. lida, T., and Guthrie, R.I.L., The Physical Properties of Liquid Metals, Clarendon, Oxford, 1988.

2. Assael M.J., Kakosimos K., Bannish M., Brillo J., Egry I., Brooks R., Quested P.N., Mills K.C., Nagashima A., Sato Y., and Wakeham W.A., "Reference Data for the Density and Viscosity of Liquid Aluminum and Liquid Iron," Phys. Chem. Ref. Data 35:285-300 (2006) or see IUPAC project 2003-005-1-100.

For more information and comments, contact Task Group Chair Marc J. Assael <assael@auth.gr> or William A. Wakeham <vice-chancellor@soton.ac.uk>.

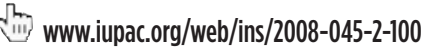

\section{A Database of Water Transitions from Experiment and Theory}

The water molecule is arguably the single most important species from a spectroscopic point of view. It is certainly molecule number 1 in the standard atmospheric database HITRAN since it is both the largest absorber of sunlight in the earth's atmosphere and the major greenhouse gas. This means, for example, that its isotopologue $\mathrm{H}_{2}{ }^{18} \mathrm{O}$ is the fifth biggest absorber in the earth's atmosphere. Water spectra are equally important astronomically: absorption by hot water dominates the atmospheres of M-dwarfs, the most common stars in our galaxy, and has recently been identified in the extra-solar planet HD189733b.

There have been many years of work and hundreds of papers on the laboratory spectroscopy of water but 